\title{
Properties Variation of Carbon Fiber Reinforced Composite for Marine Current Turbine in Seawater
}

\author{
LI Jing ${ }^{1,2,3, \mathrm{a}}$, HOU Shipu ${ }^{1,2,3, \mathrm{~b}}$, ZHAO Peng ${ }^{1,2,3, \mathrm{c}}$, JIA Penggang ${ }^{1,2,3, \mathrm{~d}}$, GE Guangnan ${ }^{1,2,3, \mathrm{e}}$, \\ LIU Yuxin ${ }^{1,2,3, \mathrm{f}}$, WEN Daowei ${ }^{1,2,3, \mathrm{~g}}$ and LI Zheng ${ }^{1,2,3, \mathrm{~h}}$ \\ ${ }^{1}$ Harbin Research Institute of Large Electrical Machinery, Harbin, 150040, China \\ ${ }^{2}$ State Key Laboratory of Hydro-power Equipment, Harbin, 150040, China \\ ${ }^{3}$ National Engineering Research Center-Hydropower Equipment, Harbin, 150040, China \\ aijing_2651@163.com, ${ }^{\mathrm{b}} 13936283233 @ 163 . c o m,{ }^{\mathrm{c}} 13845124782 @ 163 . c o m$, \\ dgupg11@163.com, ${ }^{\mathrm{e}}$ clggn_0603@163.com, ${ }^{\mathrm{f}} 296519555 @$ @q.com, ${ }^{\mathrm{g}}$ wendaowei@hec-china.com, \\ hlizheng@hec-china.com
}

\begin{abstract}
Turbine blade which are generally made of composite is a core device among components of tidal current power generator that converts the flow of tidal current into a turning force. Recent years, damages of composite turbine blades have been reported due to reasons like seawater degradation, lake of strength, manufacture etc. In this paper, water absorption, tensile, bending, longitudinal transverse shearing properties of carbon fiber reinforced plastic (CRP) composite which would be applied to fabricate the marine current turbine blade has been investigated. Furthermore, the variations of properties with seawater immersion period were studied. The results indicated that the water absorption increased almost linearly at the beginning of immersion and then became stable. Tensile strength of specimen tended to decrease firstly and then recovered slightly. However, the longitudinal transverse shearing strength showed reverse variation trend comparing to tensile strength. And the bending property of specimens was depressed significantly. The properties variations in seawater shall be referenced to design and fabrication of composite marine current turbine blade.
\end{abstract}

Keywords: Carbon fiber reinforced plastic composite; water absorption; tensile property

\section{Introduction}

In order to develop cost-effective tidal energy conversion systems, the long term reliability of turbine blades must be guaranteed[1].A turbine blade among components of a tidal current power generator is a core device that converts the flow of tidal current into a turning force[2]. However, blade failures have dogged the fledgling tidal current turbine industry and have been seriously affecting its apparent viability. Recent failures include[3]: i)blade failure on the Open Hydro 16-m turbine installed in the Bay of Fundy, NS, Canada on June 
11, 2010; ii)blade failure of the two Verdant Power tidal turbines installed in the East River of New York City on December 11, 2006; iii) the blade fracture of the Atlantis AR1000 turbine soon after its installation and connection to the grid of the European Marine Energy Centre (EMEC) in August 2010. In all cases the blade material was fiber reinforced plastic, a composite.

Generally, composites offer several advantages over metals such as superior fatigue characteristics, high stiffness to weight ratio, ease of manufacture of structures with complex curvature and a reduction in inertial loading[4]. In the recent years, the use of composites in marine applications is widespread. The two major advantages of fiber-reinforced plastics over metals are resistance to the marine environment, particularly the elimination of galvanic corrosion and the ease of tailoring structures, which are fabricated by molding processes[5]. However, being immersed in corrosive seawater can lead to degradation of certain material properties over long periods of time. Also, as the blades are submerged in water depths of greater than $20 \mathrm{~m}$, the likely maintenance windows are few and far between (due to the difficulty in accessing the blades from the surface) [6]. Therefore, the composite material used for marine turbine blades must be fabricated with excellent properties such as tensile, bending and shearing parameters in seawater environment.

Recently, the mechanical degradation behaviors have been found for composite applied for marine environment. The effect of sea water on the bearing strength behavior of the woven glass fiber composites has been studied by Alaattin et al. [7], and the results indicate that the bearing strength has been decreased significantly. Huang et al. [8] have also investigated the effect of sew water immersion on the tensile strength and bending behavior of the composites, and found that the composites have experienced significant reduction of the tensile strength, meanwhile the bending behavior was improved. Compressive behavior of carbon/epoxy composite in the deep-sea environment has also been researched by Rhee et al. [9], and the results showed that the compressive properties of sea water-absorbed carbon/epoxy composite underwent significant changes with increasing pressure.

To assume long-term durability, a fundamental understanding is essential in terms of strength and material degradation. The objective of this study is to investigate the mechanical properties degradation behaviors of the CRP under seawater conditions. Carbon fiber reinforced epoxy resin laminates were fabricated by using the vacuum assisted resin transfer moulding VARTM technique. After treatment by the artificial seawater, the weight change, the tensile strength, the bending and longitudinal transverse (L-T) shearing behaviors of the specimens were measured and analyzed.

\section{Experimental and Characterization}

\subsection{Fabrication of Carbon fiber reinforced composite}

Carbon fibers were used. The specific mass of the fibers was 6000 tex for carbon fibers with diameter of $300 \mu \mathrm{m}$. The specifications of the T300 carbon fibers used are listed in Table 1. TDE-85 epoxy resin (produced by Tianjin Institute of Synthetic Materials Industry) with epoxy value of 0.88 was introduced as the matrix, and the molecular formula is shown in Fig.1. Laminated composite plates were manufactured by VARTM technique. The curing schedule is shown in Fig.2. 
TABLE 1 SPECIFICATION OF T300 CARBON FIBERS.

\begin{tabular}{ccccccc}
\hline $\begin{array}{c}\text { Carbon } \\
\text { fiber }\end{array}$ & $\begin{array}{c}\text { No. for } \\
\text { each fiber } \\
(\mathrm{n})\end{array}$ & $\begin{array}{c}\text { Tensile } \\
\text { strength } \\
(\mathrm{GPa})\end{array}$ & $\begin{array}{c}\text { Elastic } \\
\text { modulus } \\
(\mathrm{GPa})\end{array}$ & $\begin{array}{c}\text { Elongation } \\
(\%)\end{array}$ & $\begin{array}{c}\text { Interfacial } \\
\text { shearing } \\
\text { strength }(\mathrm{MPa})\end{array}$ & $\begin{array}{c}\text { Density } \\
\left(\mathrm{g} / \mathrm{cm}^{3}\right)\end{array}$ \\
\hline T300 & 6000 & 3.80 & 231 & 2.2 & 81.5 & 1.80 \\
\hline
\end{tabular}<smiles>O=C(OCC1CO1)c1cc2c(cc1C(=O)OCC1CO1)O2</smiles>

Fig.1 The molecular formula of TDE-85 epoxy resin.

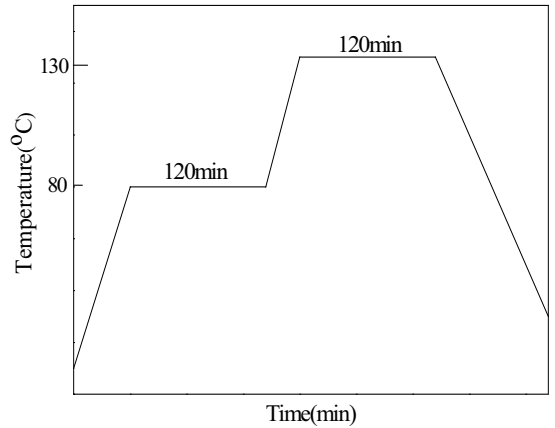

Fig. 2 Curing procedure of epoxy composite.

The composite with the same resin content were chosen and machined into the samples for seawater immersion and mechanical evaluations. The samples for tensile, bending and L-T shearing tests were cut according to the geometry and size shown in Fig.3.

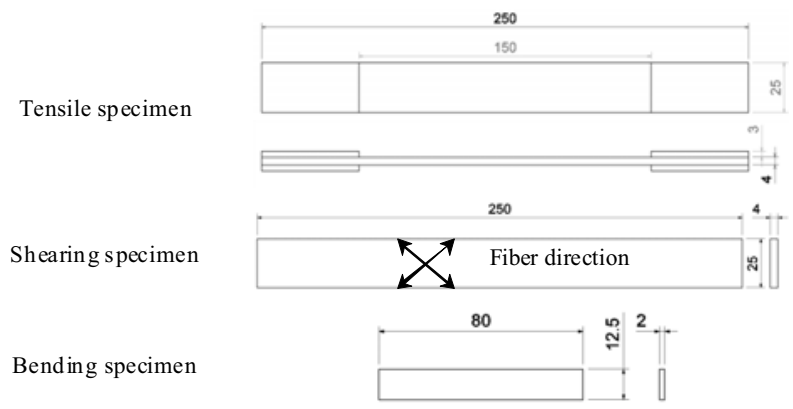

Fig.3 Specification of specimen for tensile, bending and L-T shearing tests.

\subsection{Seawater immersion test}

Before treatment in seawater, all the samples were dried until a constant weight was attained. The artificial seawater was prepared by mixing the sea salt with distilled water, and the salt concentration was controlled at $3.5 \%$. A temperature of $25^{\circ} \mathrm{C}$ was maintained throughout the treatment. Water absorption was measured using samples specified in ISO 62 "Plastic-Determination of water absorption". The specimens were then immersed in sea water at room temperature and the weigh changes were monitored as a function of time. Typically the weight of the specimen was monitored at the period of $2 \mathrm{~h}, 24 \mathrm{~h}, 48 \mathrm{~h}, 96 \mathrm{~h}$, $120 \mathrm{~h}, 144 \mathrm{~h}, 168 \mathrm{~h}, 192 \mathrm{~h}, 240 \mathrm{~h}$. Water absorptions of the samples were examined using an 
electronic analytical balance with a precision of $1 \mathrm{mg}$. it is important to note that both faces of the composite specimens were exposed to the seawater.

\subsection{Mechanical tests}

Tensile tests were performed in order to determine the influence of the water absorption on the mechanical properties. A Shimadzu AGI-250KN test machine was used to determine the monotonic tensile properties (Young's modulus E, ultimate strength, Poisson ratio) of samples. The tensile tests were conducted at room temperature, with a cross-head speed of $1 \mathrm{~mm} / \mathrm{min}$. a clip-on extensometer with $50 \mathrm{~mm}$ gauge length was used to measure strain. To minimize loss of moisture, the specimens were taken out from the water immediately before the tensile testing. Three samples were tested for each condition and the mean value of the data points obtained was taken as the measured result. Three-point-bending tests were carried out according to GB/T 3356-1999“Test method for flexural properties of unidirectional fiber reinforced plastic". The gauge length of the sample was $64 \mathrm{~mm}$ and the load was applied at the middle of the sample until the sample was fractured. The longitudinal transverse (L-T) shearing tests were carried out according to the standard GB/T 3355-2005 "Test method for longitudinal transverse shear (L-T) properties of fiber reinforced plastics" with shearing specimen in Fig.3.

\section{Results and Discussion}

\subsection{Water absorption}

Water absorption is one of the important parameters that characterize the performance change of the material in the whole degradation process. The degradation process includes physical process and the chemical process. Water absorption (M) is calculated by

$$
M=\frac{M_{1}-M_{0}}{M_{0}} \times 100 \%
$$

Where $\mathrm{M}_{0}$ is the mass at the initial state and $\mathrm{M}_{1}$ is the mass at the treated state[10].

Fig. 4 shows the water absorption of the composite as a function of immersing time. It can be seen that the water absorption almost linearly increases quickly in $48 \mathrm{~h}$ and then the increase become slow from $48 \mathrm{~h}$ to $168 \mathrm{~h}$, after that it does not change considerably. The ultimate water absorption of the composite remains at $0.11 \%$ after $240 \mathrm{~h}$ immersion. It seems that water uptake in a short period as employed in this research showed gradual increase with increased immersion days. Prolonged water immersion may finally make the sample saturated. When the samples were immersed in the seawater, the water molecules would penetrate into the materials. This would increase the sample mass. At the same time, some soluble compound would be extracted into the seawater solution which could cause the mass loss[10]. The variation of water absorption of the composition arises from the combination of these two effects. It is thought that the moisture penetrates into the materials quickly at the beginning of immersion, which induces a quickly increase for water absorption due to higher void content in the matrix and fibre-matrix interface[11]. 


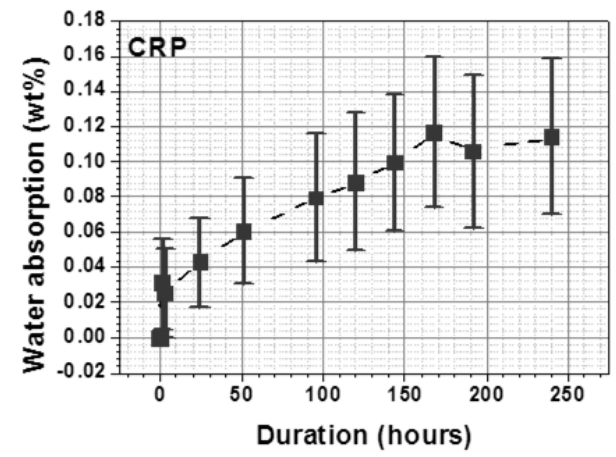

Fig.4 water uptake curve for the carbon fiber reinforced composite.

\subsection{Tensile properties}

The tensile strength variation of the seawater treated specimens is shown in Fig. 5. Each datum in the figure was based on three determinations. The ultimate strength of untreated composite specimen is $1415 \mathrm{MPa}$. The deceased trend of the tensile strength with increased treating time might be seen at the beginning 40 days of immersion, and the strength decreased to $1190 \mathrm{MPa}$. Voids and cracks of the resin would allow moisture to penetrate the composites, which amplified and accelerated the breakdown of the structure[11]. With the seawater treatment period increased from 40days to 120days, the ultimate strength of specimen recovered to $1320 \mathrm{MPa}$, which is close to the original strength value.

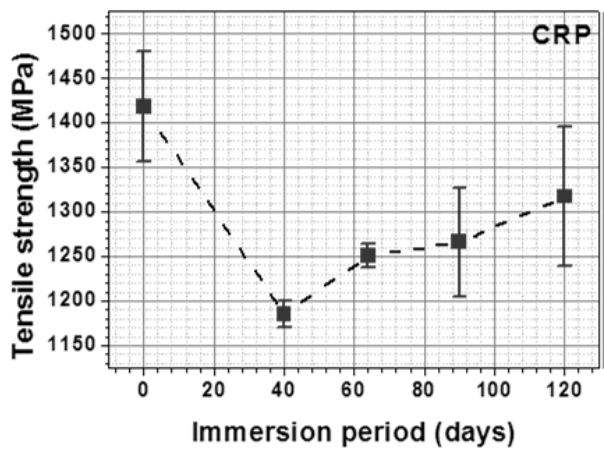

Fig.5 Effect of seawater immersion time on tensile strength of CRP.

Fig. 6 shows the elastic modulus of carbon fiber reinforced composite specimen variation with the seawater immersion increasing. Almost the same trend was found for elastic modulus to the ultimate strength. The elastic modulus of untreated specimen is about 106GPa. As the immersing time increased, the elastic modulus decreased to $97 \mathrm{GPa}$ for 63days, and then recovered to $103 \mathrm{GPa}$ for 120 days immersion. However, the variation of Poison ratio shown in Fig.7 for composite specimen immersed at different period is slightly, which varied from 0.3 to 0.39 . 


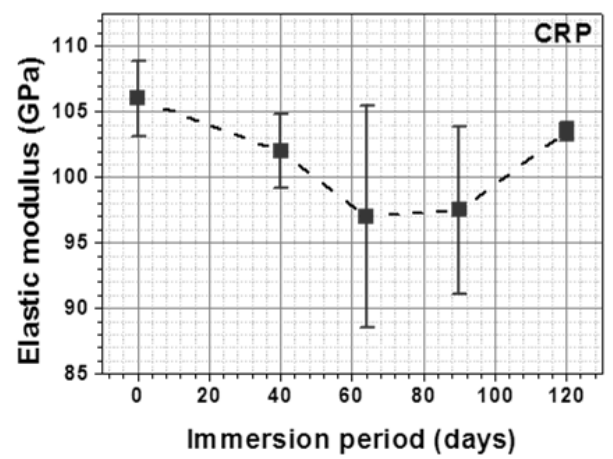

Fig.6 Effect of seawater immersion time on elastic modulus of CRP.

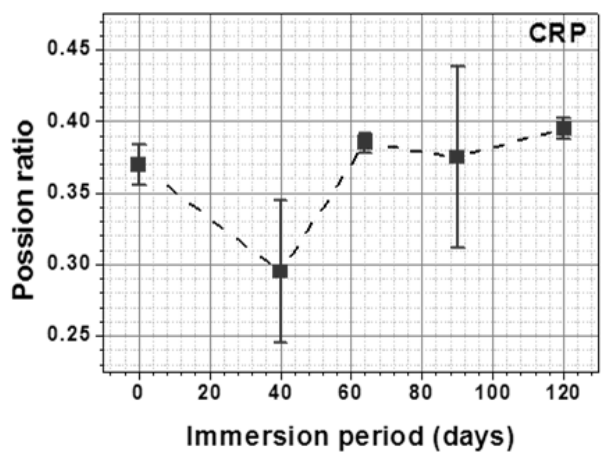

Fig.7 Effect of seawater immersion time on

Poisson ratio of CRP.

\subsection{Bending properties}

Fig. 8 illustrates the bending strength of the seawater treated specimens. The bending strength of untreated composite specimen is about $1850 \mathrm{MPa}$. A decreasing trend of the bending resistance with prolonged immersion time could be noticed in the figure, especially in the beginning of 21 days. Statistic calculations were made for each case to see if the bending strength decrease was significant. From the figure one might see that the reduction of the bending strength was significant. The bending strength of the specimen was reduced to $1450 \mathrm{MPa}$ after immersion period of 21 days. And then, the bending strength decreased $25 \%$ comparing to the original value, which is only $1400 \mathrm{MPa}$.

Fig. 9 shows the variation of bending energy consumed for breaking the specimen. The results indicate that carbon reinforced composited tended to be bended into broken more easily after immersion in seawater at the beginning. However, after immersion for 21 days, the bending energy changes slightly with the immersion period. Same variation trends occurred for max strain value for bending the specimen into broken. The max strain value is about $1.5 \%$ after immersion period of 63 days. The results show that the bending properties of carbon reinforced composite immersed in seawater was depressed significantly, and the specimens were easily bended into broken compared to untreated materials.

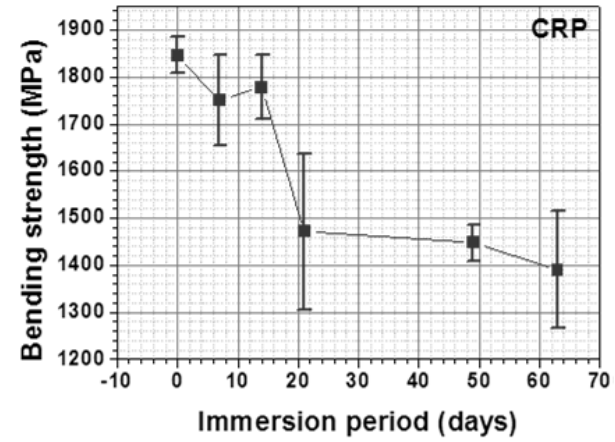

Fig.8 Effect of seawater immersion time on bending strength of CRP.

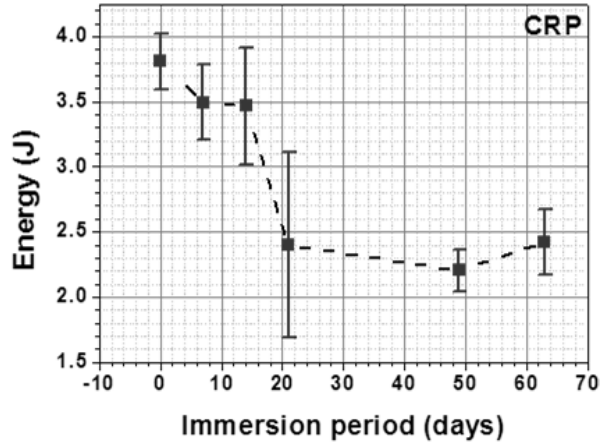

Fig.9 Effect of seawater immersion time on bending energy of CRP. 


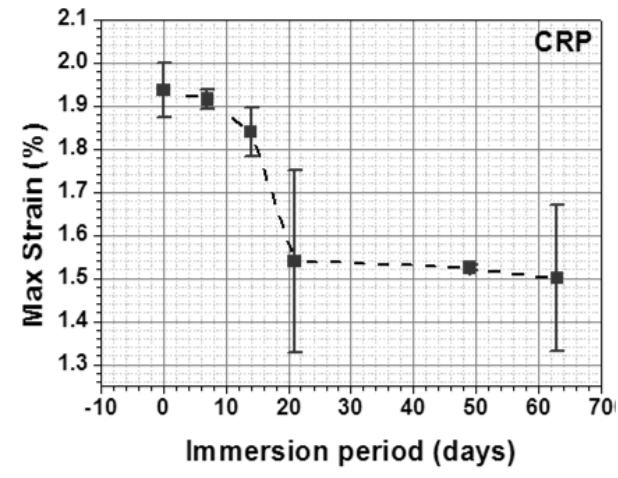

Fig.10 Effect of seawater immersion time on max bending strain of CRP.

\subsection{Longitudinal transverse (L-T) shear properties}

Fig.11 shows the longitudinal transverse (L-T) shearing strength variation of specimens with immersion period in seawater. At the beginning of 42 days, the L-T shearing strength tends to be increased from $208 \mathrm{MPa}$ to $220 \mathrm{MPa}$. Then the L-T shearing strength was slightly decreased to $216 \mathrm{MPa}$ after immersion in seawater for 63 days. The results indicates that the L-T shearing strength was enhanced for carbon reinforced composite immersion in seawater.

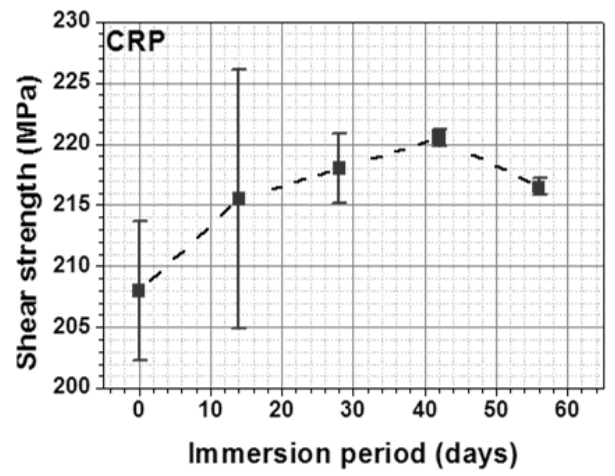

Fig.11 Effect of seawater immersion time on L-T shearing strength of CRP.

\section{Summary}

The effect of water absorption on the mechanical properties of carbon fiber reinforced composite has been studied following immersion in seawater at room temperature. From the results obtained the following conclusion can be drawn:

1) The water absorption almost linearly increases quickly in $48 \mathrm{~h}$ and then the increase become slowly from $48 \mathrm{~h}$ to $168 \mathrm{~h}$, after that it does not change considerably. The ultimate water absorption of the composite remains at $0.11 \%$ after $240 \mathrm{~h}$ immersion.

2) The deceased trend of the tensile strength with increased treating time might be seen at the beginning 40 days of immersion, and the strength decreased to $1190 \mathrm{MPa}$. As seawater treatment period further increased, the ultimate strength of specimen recovered to $1320 \mathrm{MPa}$.

3) The bending properties of carbon reinforced composite immersed in seawater was depressed significantly, and the specimens were easily bended into broken compared to 
untreated materials.

4) The L-T shearing strength was enhanced for carbon reinforced composite immersion in seawater.

\section{Acknowledgments}

The financial support from China National Ocean Bureau under contract no. GHME2010CY01 and the research fund of Heilongjiang Province Postdoctoral Scientific Research Development Fund support no. LBH - Q14033 are gratefully acknowledged.

\section{References}

1. B. Gaurier, P. Davies, A. Deuff, G. Germain, Flume tank characterization of marine current turbine blade behaviour under current and wave loading, Renewable Energy, 59 (2013) 1-12.

2. C.h. Jo, J.y. Yim, K.h. Lee, Y.h. Rho, Performance of horizontal axis tidal current turbine by blade configuration, Renewable Energy, 42 (2012) 195-206.

3. P. Liu, B. Veitch, Design and optimization for strength and integrity of tidal turbine rotor blades, Energy, 46 (2012) 393-404.

4. R.F. Nicholls-Lee, S.R. Turnock, S.W. Boyd, Application of bend-twist coupled blades for horizontal axis tidal turbines, Renewable Energy, 50 (2013) 541-550.

5. K.V. Arun, S. Basavarajappa, B.S. Sherigara, Damage characterisation of glass/textile fabric polymer hybrid composites in sea water environment, Materials \& Design, 31 (2010) 930-939.

6. D.M. Grogan, S.B. Leen, C.R. Kennedy, C.M. Ó Brádaigh, Design of composite tidal turbine blades, Renewable Energy, 57 (2013) 151-162.

7. A. Aktaş, İ. Uzun, Sea water effect on pinned-joint glass fibre composite materials, Composite Structures, 85 (2008) 59-63.

8. G. Huang, H. Sun, Effect of water absorption on the mechanical properties of glass/polyester composites, Materials \& Design, 28 (2007) 1647-1650.

9. K.Y. Rhee, S.M. Lee, S.J. Park, Effect of hydrostatic pressure on the mechanical behavior of seawater-absorbed carbon/epoxy composite, Materials Science and Engineering: A, 384 (2004) 308-313.

10. B. Wei, H. Cao, S. Song, Degradation of basalt fibre and glass fibre/epoxy resin composites in seawater, Corrosion Science, 53 (2011) 426-431.

11. H. Gu, Behaviours of glass fibre/unsaturated polyester composites under seawater environment, Materials \& Design, 30 (2009) 1337-1340. 